\title{
Forma-memoria poliuretano biobateragarriak
}

\section{(Shape Memory Biocompatible Polyurethanes)}

\author{
Saioa Sierra, Antonio Veloso* \\ Kimika Fisikoa Saila, Zientzia eta Teknologia Fakultatea FCT/ZTF, \\ Euskal Herriko Unibertsitatea (UPV/EHU)
}

LABURPENA: Plastikoak gero eta gehiago erabiltzen diren materialak dira biomedikuntzaren arloan, baina beharrezkoa da material horiek arlo honetako zenbait kasutan erabiltzeko biobateragarriak izatea. Horren ondorioz, ezinbesteko erronka da plastiko biobateragarrien garapena. Poliuretanoak oso konposatu erabiliak dira, dituzten aldakortasun eta aplikazio ugariei esker. Horien artean, forma-memoria duten poliuretanoak daude. Horiek estimulu baten aurrean forma aldatzeko gaitasuna dute, eta, horrela, erabilgarriak izan daitezke beste polimero batzuekin lortu ezin diren aplikazioetan. Bestalde, garrantzitsua da materialen biobateragarritasuna eta toxikotasuna ezagutzea eta aztertzea, kutsadura murrizteko helburuarekin. Izan ere, gaur egun, oraindik garapen handia falta da ingurumena kaltetzen ez duten materialen sintesian. Lan honetan, biobateragarriak diren forma-memoria poliuretanoetan sakonduko da.

HITZ-GAKOAK: poliuretanoak, forma-memoria polimeroak, biobateragarritasuna, toxizitatea.

ABSTRACT: Plastics are increasingly used in the field of biomedicine, but their use in some cases requires biocompatibility. Thus, the development of biocompatible plastics is a mandatory challenge. The polyurethanes are very used materials, owing to their variability and multiple applications, among which are the polyurethanes with shape memory. These, with their singular features, like the capacity to change their shape when receiving an external stimulus, have reached the utility in the fields where others did not. On the other hand, the biodegradability and the toxicity of the materials is another important matter to consider, with the aim of reducing pollution. In fact, there is still so much progress to work on in the synthesis of the non-harmful materials for the environment. Therefore, in this work it will go in depth about biocompatible shape-memory polyurethanes.

KEYWORDS: polyurethane, shape memory polymers, biodegradability, toxicity.

\footnotetext{
* Harremanetan jartzeko / Corresponding author: Antonio Veloso Fernández. Kimika Fisikoa Saila, Zientzia eta Teknologia Fakultatea, Euskal Herriko Unibertsitatea UPV/EHU, Sarriena auzoa z/g, 48940 Leioa, Bizkaia. - antonio.veloso@ehu.eus - https:// orcid.org/0000-0003-1309-2373

Nola aipatu / How to cite: Sierra, Saioa; Veloso, Antonio (2021). "Forma-memoria poliuretano biobateragarriak». Ekaia, 40, 2021, 273-289. (https://doi.org/10.1387/ekaia.21810).

Jasotze-data: 2020,ekainak 11; Onartze-data: 2021, otsailak 12.

ISSN 0214-9753 - elSSN 2444-3581 / (c) 2021 UPV/EHU
}

cc)()ㅇ Lan hau Creative Commons Aitortu-EzKomertziala-LanEratorririkGabe 4.0 Nazioartekoa lizentzia baten mende dago 


\section{SARRERA}

Plastikoak zenbait arlotan erabiltzen diren materialak dira, eta biomedikuntzan gero eta gehiago ari dira erabiltzen. Arlo horretan, plastikoak oso erabilgarriak dira protesiak egiteko; gainera, metalezko protesiekin konparatzen baditugu, plastikozkoak merkeagoak dira, eta askoz errazago prozesatzen dira. Hala ere, gure gorputzean plastiko bat sartzeko, beharrezkoa da biobateragarria eta ez-toxikoa izatea. Beraz, ezinbesteko erronka da biobateragarriak eta ez-toxikoak diren plastikoen ikerketa bermatzea.

Forma-memoria ezaugarria duten polimeroek, kanpoko estimulu baten ondorioz, forma aldatzeko gaitasuna azaltzen dute. Ezaugarri horrek aplikazio askotarako erabilgarriak izatea eragiten du; hala nola, medikuntzaren esparruan. Horien artean forma-memoria poliuretanoak daude, eta, azaltzen duten forma-memoria ezaugarri hobeezinei esker, erabilienak dira. Horrela, gaur egun asko erabiltzen diren konposatuak dira poliuretanoak (PU), eta aztertu da hurrengo urteetan gehiago erabiltzen jarraituko dela, ingurumena errespetatzeko eta ez kaltetzeko eskaintzen duten aukera dela eta [1].

Lan honetan, forma-memoria duten poliuretano biobateragarrietan sakonduko dugu. Lehenengo, forma-memoria zer den eta nola agertzen den aztertuko da. Horretarako, azterketa termomekanikoa (TMA) erabiliko da. Ondoren, biobateragarritasun kontzeptuak zer esan nahi duen aztertuko dugu. Kasu horretan, bideragarritasun zelularra aztertuko da bromuro 3(4, 5 dimetil-2-tiazoil)-2,5-difeniltetrazolikoaren (MTT) erredukzioaren bidez. Azterketa horietan lortutako emaitzak aztertuta, lagin horiek biomedikuntza-aplikazioetan egokiak diren ala ez zehaztuko da.

\subsection{Forma-memoria}

Forma-memoria efektua gauzatzean, lehenengo materiala hasierako formatik (hau da, behin betiko formatik) behin-behineko forma batera eraldatzen da indar baten eraginez. Ondoren, soilik kanpo-estimuluaren ondorioz, materialak behin betiko forma berreskuratzeko gaitasuna azalduko du.

Forma-aldaketa eragiteko kanpo-estimulu ugari daude - hala nola, termikoa, kimikoa, erradiazioa, $\mathrm{pH}$-aren aldaketa, magnetikoa, elektrikoa edota foto-indukzioaren bidez ematen direnak -, eta termikoa da ohikoena. Polimeroaren egituraren eta konposizioaren araberakoak izango dira horiek [2]. 1. irudian, forma-memoria efektuaren eskema orokorra ikus daiteke.

Termoinduzitutako efektua materiala beira-trantsizioko tenperaturaren (glass transition temperature, $\mathrm{T}_{\mathrm{g}}$ ) gainetik eta azpitik berotzean eta/ 
edo hoztean oinarritzen da; trantsizio horretan, materiala egoera zurrunetik egoera elastikora pasatzen da. Polimeroak, ezaugarri hori azaltzeko, bere egituran segmentu biguna eta segmentu gogorra osatzen duten segmentuak azaldu behar ditu. Erraza da hori ohiko erreakzio baten bidez lortzea, eta horrek eragin du gehien erabiltzen den estimulua izatea hori. Gainera, polimeroen konposizioaren arabera, $\mathrm{T}_{\mathrm{g}}$ balioa aldatu egingo da, eta helburu duten aplikaziora egokitu. Ezaugarri hori duten polimeroen artean daude, esaterako, poliesterrak, poliestirenoa, estireno akrilatoak eta poliuretanoak, eta, lehen aipatu den moduan, azken horiek aztertu eta garatuko dira lan honetan. 2. irudian, PUen egitura molekular eskematikoa erakusten da [2].

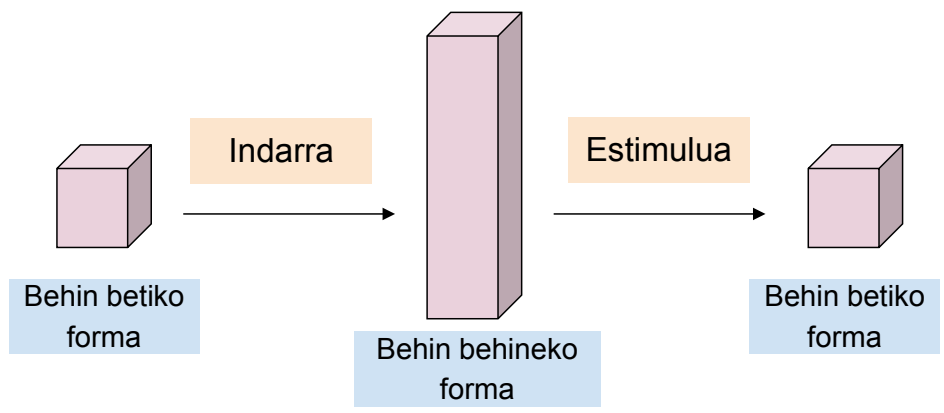

1.irudia. Forma-memoria orokorraren eskema.

$$
\left[\mathrm{R}^{1}-\mathrm{O}-\mathrm{O}_{\mathrm{O}}^{\mathrm{C}-\mathrm{N}} \underset{\mathrm{H}}{\mathrm{H}-\mathrm{R}^{2}-\mathrm{N}-\mathrm{H}}{ }_{\mathrm{O}}^{\mathrm{C}}-\mathrm{O}\right]_{\mathrm{n}}
$$

2. irudia. Poliuretanoaren egitura eskematikoa.

Tenperatura igo ondoren, materiala deformatu egiten da. Eraldaketa horren ondoren, egokitu zaion forma mantenduz hozten bada, berriro egoera zurrunera bueltatuko da, baina izaera ez-egonkorrean, hau da, behin-behineko forman. Berriro trantsizioko tenperaturatik gora berotzen bada, hasierako formara itzuliko da, hau da, eraldatu gabeko edo behin betiko formara.

Efektu hori gauzatzean, interesgarria da poliuretanoaren egitura molekularrean gertatzen den prozesua aztertzea (3. irudia). Polimeroa beira-trantsizioko tenperaturaren gainetik berotzean, kate askeek 
mugikortasuna azalduko dute, konposatuaren deformazioa ahalbidetuz. Tenperatura trantsizioko tenperaturatik jaistean, kate horietan egitura erdikristalinoak eratuko dira, eta horiek egonkor mantenduko dute behin-behineko forma. Gainera, tenperatura jaitsi egingo denez, kateek ez dute mugitzeko gaitasunik izango, eta ezingo da hasierako formara itzuli. Egoera horretan, kateen ordenamendua handitu egingo da, eta entropia txikitu. Berriro tenperatura handitzen denean $\left(\mathrm{T}>\mathrm{T}_{\mathrm{g}}\right)$, kateek mugikortasuna berreskuratuko dute, eta materialak hasierako forma berreskuratzeko joera azalduko du. Entropia handiagoko egoerara bueltatuko da; hau da, energia gutxieneko eta egonkorreneko formara [3, 4]. Polimeroaren egitura kimikoa eta morfologia kontrolatzean eta deformazio-pausoan baldintzak optimizatzean, hobetu daiteke forma-memoriaren etekina [5].

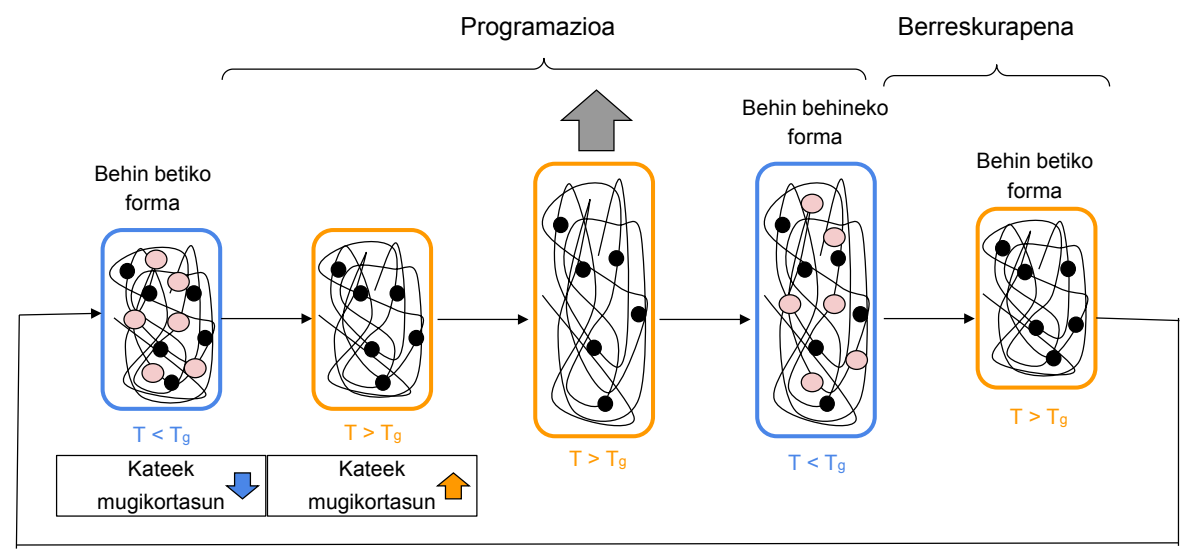

3. irudia. Forma-memoria egitura molekularraren eskema.

Material horien erabilerari dagokionez, medikuntzaren arloan abantaila anitzak azaltzen dituzte, bai material kirurgiko bai inplante modura. Izan ere, material horiek biobateragarriak eta ez-toxikoak izan daitezke; baldintza hori ezinbestekoa da medikuntzaren arlorako, eta konposizioaren arabera erregulatu egin daiteke bere aktibazio-tenperatura. Beste teknologien laguntzarekin, protesi eta pazientearentzat gailu pertsonalizatuak sor daitezke [2].

\subsection{Poliuretanoak}

Poliuretanoak (PUak) hainbat aplikaziotarako erabiltzen diren materialak dira, eta, helburutzat duten aplikazioaren arabera, egitura makromolekular desberdina sintetizatu eta erabiliko da, termoplastikoa edo termoegonkorra, hain zuzen $[6,7]$. 
Poliuretano-barietate zabal hori posiblea da sintesirako dagoen monomero mota desberdinen eskuragarritasunaren ondorioz. Sintesian makrodiol, isozianato (bifuntzionala gehienetan, diisozianato edo polifuntzionala, poliisozianato) eta kate hedatzaile (kate motzeko alkohol edo amina) bat erabiltzen dira, eta izugarria da hiru horien aniztasuna. Horrela, di- edo poliisozianatoaren eta di- edo poliol baten erreakzioaren bidez, poliuretanoaren prepolimeroa eskuratuko da, eta, kate hedatzailea gehitu ondoren, poliuretanoa sintetizatuko da (4. irudia) [8].

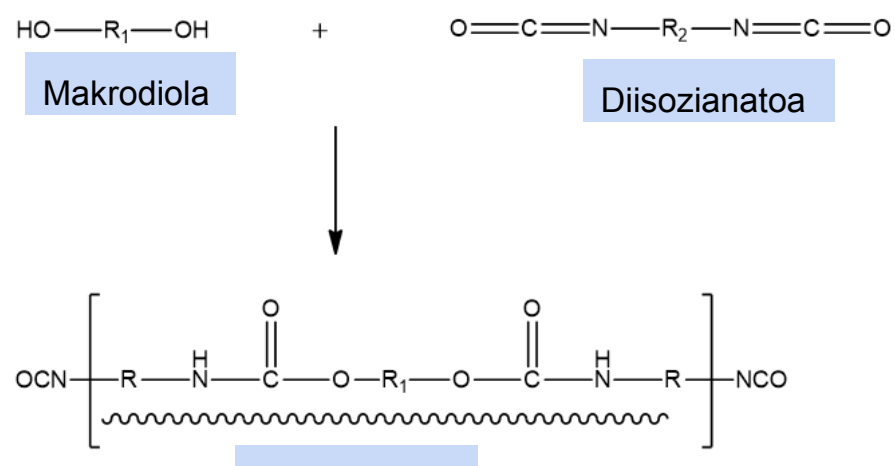

Prepolimeroa

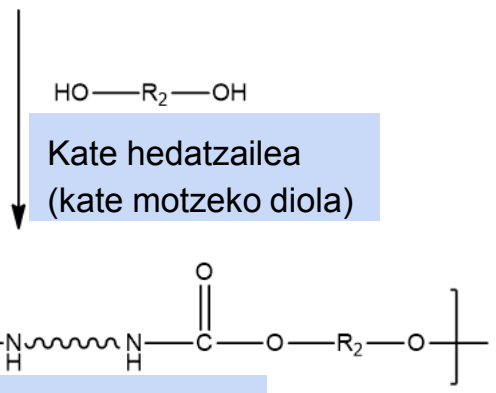

Bukaerako poliuretanoa

4. irudia. Poliuretanoaren sintesi eskematikoa, prepolimerotik igaroz.

Poliuretanoa polimero berezia da, bere egituran segmentu bigun eta segmentu gogor bat dauzkana. Segmentu horien arteko ezaugarrien desberdintasunak eta bateraezintasunak fase-bereizketa eragiten du bukaerako materialean. Segmentu gogorra diisozianatoz eta kate hedatzailez osatuta dago; segmentu biguna, berriz, kate luzeko polieter edo poliester glikolez (poliol), 5a. irudian ikusten den bezala [5, 8, 9]. 


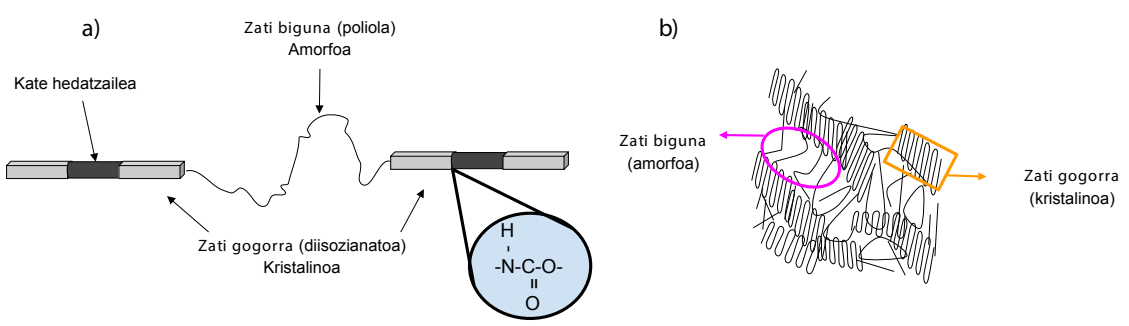

5. irudia. Poliuretanoen egitura: a) oinarrizko egitura eta b) egitura osatua.

Segmentu gogorra - fase «izoztua» eta kristalinoa - talde polarrez osatuta dago. Talde horien artean sortzen diren hidrogeno-loturei eta dipolo-dipolo elkarrekintzei esker, ordenatuta azaltzen diren domeinuak eratzen dira, eta segmentu gogorrak elkarrekin mantentzen dira. Hala ere, segmentu gogorra amorfoa ere izan daiteke. Horiek segmentu bigunaren (domeinu amorfoa) matrizean sakabanatuta daude, orokorrean egitura zatikatu bat eratuz eta mikrofase-bereizketa bat agertuz (5b. irudia). Horren ondorioz, segmentu gogorraren eta bigunaren faseak gehiago bereizten dira, eta ezaugarri horrek poliuretanoetan forma-memoria propietateak hobeak izatea eragiten du. Propietate horri esker, materiala trantsizio-tenperaturatik gora berotzen denean, bere hasierako forma berreskuratuko du $[5,7,8]$.

Segmentu gogorra hasierako formaren arduraduna da, eta, ondorioz, kate hedatzaileak eragina izango du forma-memoriaren errendimenduan. Kate hedatzailearen mota eta kantitatea (erlazioa), segmentu gogorraren ezinbesteko konposatua dena, parametro garrantzitsua izango da, erlazio eta eragin zuzena baitauka polimeroaren morfologiarekin eta propietate termiko, mekaniko eta fisikoekin [5].

Segmentu biguna domeinu amorfoa da, eta trantsizio-tenperatura finkatu eta bertan deformazioa jasango du; hau da, aldaketa molekular itzulgarri bat izango da. Horren ondorioz, segmentu horren kantitatea handitzean, hau da, segmentu horren pisu molekularra handitzean, segmentu gogorrak matrize bigunetik gehiago bereiziko dira, eta horrek forma berria finkatzen lagunduko du. Horrela, $T_{g}$ balioa txikitu egingo da, eta baita hasierako forma berreskuratzeko ahalmena ere. Beraz, parametro garrantzitsuak izango dira segmentu horren pisu molekularra eta poliolaren kantitatea $[5,8,10]$.

Forma-memoriaren ahalmena aurretik azaldutako segmentu gogorraren (zurruna) eta bigunaren (malgua) ondorioa da. Segmentu gogorraren ondorioz, erresistentzia mekanikoa dago, eta horrek, eraldatu ondoren, hasierako forma gogoratzea eta berreskuratzea ahalbidetzen du. Bestalde, barreiatu ahal izateko behar den energia segmentu bigunean metatzen da, materialaren deformazioa ahalbidetuz eta behin-behineko forma finkatuz. Metaketa horren 
ondorioz, kanpo-estimuluaren ondoren, nahiko energia izango du poliuretanoa hasierako formara bueltatzeko, eta horrek berreskuratze-tenperatura finkatuko du $[9,11]$.

\subsection{Biobateragarritasuna}

Biobateragarritasuna bio- (grekozko ßıo, «bizitza, izaki bizia») eta bateragarritasun («honekin egoteko gaitasuna») hitzen arteko terminoa da. Material batek erabiltzen duen ingurune biologikoaren (gizaki baten edo beste izaki bizidun baten) erantzun egokiarekin jarduteko duen gaitasuna da. Ezin da nahasi termino hori biodegradagarritasunarekin. Biodegradagarritasuna da material batek degradatzeko duen ahalmena. Prozesu naturala da, zeinetan material bat eragin biologiko baten bidez aldatu egiten baita eta aldaketa horien ondorioz normalean bere jatorrizko propietateak galtzen baititu. Kimika mailan, polimeroa osatzen duten molekulak forma sinple eta egonkorretara eraldatzen dira. Horrela, karbonoz osatutako materialak egoera oxidatuenera $\left(\mathrm{CO}_{2}\right)$, egoera erreduzituenera $\left(\mathrm{CH}_{4}\right)$ edo bien nahasketara eraldatzen dira. Edozein material organiko eragile biologikoen bidez degrada daiteke, hala nola landare, animalia, mikroorganismo edota onddoen bidez, ingurune-egoeretan. Eragile biologiko horiek substratu modura erabiliko dute materiala, karbonoen edo beste elikagaien iturri bezala.

Polimeroak substantzia organikoak dira, lehengai sintetiko edo natural desberdinen arteko erreakzio kimikoen ondorioz lortzen direnak. Itxura askotan moldatuak eta prozesatuak izan daitezke, presioaren eta tenperaturaren eraginez. Oinarri biologikoa duten polimeroak bioplastiko izenarekin ere ezagutzen dira. Material horietan, gutxienez segmentu batek biomasatik eratorri behar du (hau da, landare, animalia, onddo edo bakterio). Lan honetan, jatorria landare batean duen errizino-olio esentziala erabiliko da [6], eta lortutako polimeroen biobateragarritasuna aztertuko da.

\section{PROZEDURA ESPERIMENTALA}

Atal honetan, poliuretanoen sintesian erabilitako erreaktiboak erakutsiko dira, eta aurrera eramandako sintesi-prozesua azalduko da.

\subsection{Erreaktiboak}

Poliuretanoen sintesirako, eter motako poliola, bi diisozianato eta bi kate hedatzaile desberdin erabiliko dira (6. irudia). Poliol modura politetrametilenglikola (PTMG) konposatua erabiliko da, bi pisu molekular desberdinekin: $650 \mathrm{~g} / \mathrm{mol}$ (PTMG650) eta $1.000 \mathrm{~g} / \mathrm{mol}$ (PTMG1000). Erabilitako diisozianato bat isoforona diisozianatoa da (IPDI), zikloalifatikoa, eta pisu molekularra $222,3 \mathrm{~g} / \mathrm{mol}$ eta dentsitatea $1,062 \mathrm{~g} / \mathrm{mL}$ dituena; bestea hexametilo diiso- 
zianatoa (HDI) da, alifatikoa, eta pisu molekularra $168,19 \mathrm{~g} / \mathrm{mol}$ eta dentsitatea $1,047 \mathrm{~g} / \mathrm{mL}$ dituena. Azkenik, bi kate hedatzaile erabili dira, 1,4-butanodiola (BD) eta errizino-olioa. BDren pisu molekularra $90,12 \mathrm{~g} / \mathrm{mol} \mathrm{da}$, eta dentsitatea $1,017 \mathrm{~g} / \mathrm{mL}$. Errizino-olioaren pisu molekularra $933,4 \mathrm{~g} / \mathrm{mol}$ da, eta dentsitatea $0,961 \mathrm{~g} / \mathrm{mL}$.

Erreaktibo horien nahaste-konposizioa aldatuz, propietate desberdinak dituzten poliuretanoak sintetizatuko dira, segmentu gogor-bigun konposizioa aldatzen baita. Horrela, izango duen erabilerarako nahaste eta konposizio optimoa dituen konposatua zein den zehazten saiatuko da.

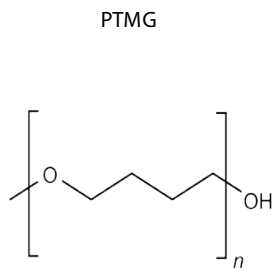

$\mathrm{BD}$
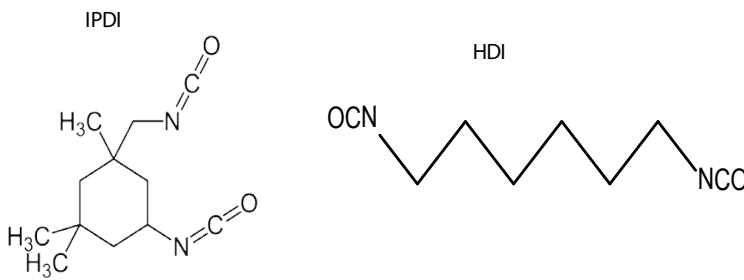

CO

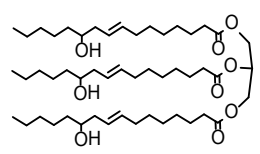

6. irudia. Erabilitako erreaktiboen egitura molekularrak: isoforona diisozianatoa (IPDI); hexametilen diisozianatoa (HDI); politetrametilenglikola (PTMG); 1,4, butanodiola (BD) eta errizino-olioa (CO) (ezkerrekoa, azido errizinoleikoa, eta eskuinekoa, horren triglizeridoa).

\subsection{Poliuretanoaren sintesia}

Erabilitako hiru erreaktiboak estekiometria hau erabilita nahasi dira: poliola: diisozianatoa: kate hedatzailea, 1: N+1: N. N balioak 1-6 artean kokatu dira, banaka zenbakia handituz, eta horiek sintetizaturiko polimeroaren ezaugarrien arabera aldatu dira, zenbaki hori gehiago handituz edo guztiak ez sintetizatuz. Horrela, sintetizaturiko PUetan $\mathrm{NCO} / \mathrm{OH}=1$ izatea lortzen da, egitura linealak lortzeko helburuarekin [12].

Sintesi guztiak bi etapatan gauzatu dira prepolimero-metodoa erabilita (1.2 atala); horrela, gainera, katalizatzailearen beharra ekidin da [12]. Lehenengo, sintesiaren baldintzak finkatu dira. Horretarako, beste lan batzuk aztertu dira, eta erreakzioa $70^{\circ} \mathrm{C}$-tan gauzatzea erabaki da $[8,12]$. Erreakzioa bost ahotako matraze borobilean $(250 \mathrm{~mL})$ gauzatu da, irabiaketa konstantean $(\approx 250 \mathrm{rpm})$. Sintesia atmosfera inertean egin da, nitrogenoaren injekzioaren bidez, bestelako bigarren mailako erreakziorik izan ez dezan. 
Sintesiarekin hasteko, lehenengo poliola (PTMG650 edo PTMG1000) eta diisozianatoa (IPDI edo HDI,) gehitu dira, eta ondoren 2 orduz erreakzionatzen utzi da, prepolimeroa lortzeko. Ondoren, kate hedatzailea (BD edo CO) gehitu da, eta erreakzioa 10 minutuz utzi da.

Kate hedatzaile oso higroskopikoak erabili direnez, erreakzioan ur kantitate handia sartzea eragin dezake horrek, eta oso erreaktiboa den isozianatoarekin bigarren mailako erreakzioak eragin. Beraz, hori ekiditeko, aldez aurretik kate hedatzaileak hutsean eta olio-bainutan lehortu dira $\left(80^{\circ} \mathrm{C}\right)$, 24 orduz, gutxi gorabehera.

Erreakzio-denbora pasatu ondoren, produktu nahiko likidoa lortu da, eta hori karratu-zulo forma daukaten plaka metalikoen gainean isuri da. Plaka hori beste batekin itxiz eta itsastea ekiditeko azetatoa erdian kokatuz, prentsa hidraulikoan sartu da, 24 orduz eta $100^{\circ} \mathrm{C}$-tan, $100 \mathrm{~kg} \cdot \mathrm{cm}$-2-ko presioan gutxi gorabehera. Lehen esan bezala, erreakzio-denbora luzea da, katalizatzaileen erabilera saihestu dugulako. Horrela, denbora hori igaro ondoren, amaitutzat eman da erreakzioa. $50 \times 50 \times 1,5 \mathrm{~mm}^{3}$ tamaina duten PU xaflak eskuratu dira, eta ondorengo karakterizazioak eta neurketak egiteko erabili dira horiek.

1. taula. Forma-memoria poliuretanoen erreaktiboen nahasteak.

\begin{tabular}{c|c|c}
\hline Poliola & Isozianatoa & Kate hedatzailea \\
\hline \multirow{4}{*}{ PTMG650 } & \multirow{3}{*}{ IPDI } & $\mathrm{BD}$ \\
\cline { 3 - 3 } & & $\mathrm{CO}$ \\
\cline { 3 - 3 } & \multirow{3}{*}{ HDI } & $\mathrm{BD}+\mathrm{CO}$ \\
\cline { 3 - 3 } & & $\mathrm{BD}$ \\
\hline \multirow{3}{*}{ PTMG1000 } & \multirow{3}{*}{ IPDI } & $\mathrm{CO}$ \\
\cline { 3 - 3 } & & $\mathrm{BD}+\mathrm{CO}$ \\
\cline { 3 - 3 } & & $\mathrm{BD}$ \\
\cline { 3 - 3 } & \multirow{3}{*}{ HDI } & $\mathrm{CO}$ \\
\cline { 3 - 3 } & & $\mathrm{BD}+\mathrm{CO}$ \\
\hline
\end{tabular}

1. taulan, lan honetan sintetizatu eta aztertu diren forma-memoria poliuretano (SMPU) guztiak agertzen dira. Esan den bezala, erabilitako SMPUtan beti poliol, isozianato eta kate hedatzailea/k agertzen dira. Horregatik, 
lan honetan erabili diren laginak deskribatzeko, beti terminologia berdina erabiliko da, eta $\mathrm{N}$ zenbakia ere adieraziko da. Sintesi-nahaste bakoitzean, $\mathrm{N}$ balio desberdineko (N1-N7) nahasteen laginak sintetizatu dira.

\subsection{Karakterizazio-teknikak}

\subsubsection{Ekorketazko kalorimetria diferentziala}

Ekorketazko kalorimetria diferentziala (Diferential Scaning Calorimetry, DCS) bero-aldaketa izaten duten prozesuak aztertzeko teknika da, bero espezifikoa, lurruntze- edo urtze-puntua, $\mathrm{T}_{\mathrm{g}}$ balioa, konposatu kristalinoen purutasuna edota erreakzioen entalpiak aztertzeko, besteak beste.

Orokorrean, teknika honen lan-tartearen tenperatura nitrogeno likidoaren tenperaturatik $\left(-195^{\circ} \mathrm{C}\right) 600^{\circ} \mathrm{C}$ tenperatura ingurura doa. Horren ondorioz, teknika hau erabiltzen da tenperatura-tarte horretan trantsizio termiko bat jasaten duten materialak aztertzeko.

Poliuretanoen material-familiak tenperatura-tarte horretako trantsizio termiko guztiak jasaten ditu. Horregatik, teknika hau material horien karakterizazioa gauzatzeko erabiltzen da, batik bat. Trantsizio termikoak azter daitezke, beira-trantsizioko tenperatura $\left(\mathrm{T}_{\mathrm{g}}\right)$ eta fusio-tenperatura $\left(\mathrm{T}_{\mathrm{m}}\right)$ adibidez.

Teknika horren bidez, trantsizio termikoak aztertzeaz aparte, igorritako edo hartutako bero kantitatea ere zehatz daiteke, eta hori aldaketa fisiko edo kimiko baten ondorioa izango da. Bero-aldaketa horiek eragina dute materialaren barne-energian, eta presio konstantean gauzatzen bada, entalpia $(\Delta \mathrm{H})$ modura ezagutzen da.

Lan honetan, materialaren trantsizio-tenperaturak zehaztuko dira teknika horren bidez. Kasu honetan, zehaztu nahi dugun tenperatura beiratrantsizioko tenperatura $\left(\mathrm{T}_{\mathrm{g}}\right)$ izango da. Horretarako, METTLER TOLEDO DSC 822e kalorimetroa erabiliko dugu. Bertan, lagina barnean kokatuta daukan aluminio-kapsula bat sartuko da (gutxi gorabehera $10 \mathrm{mg}$ ), eta tenperatura-aldaketekin hasiko da.

Lehenengo tenperatura-aldaketan, lagina $-100^{\circ} \mathrm{C}$-tik $250^{\circ} \mathrm{C}$-ra berotuko $\mathrm{da}, 10^{\circ} \mathrm{C} / \mathrm{min}$ abiadura konstante mantenduz. Ondoren, tenperaturaren beherakada gertatuko da, $250^{\circ} \mathrm{C}$-tik $-100^{\circ} \mathrm{C}$-ra, eta, azkenik, hirugarren tenperatura-aldaketan, lagina berriro berotuko da, lehenengoan bezala, $-100^{\circ} \mathrm{C}$-tik $250^{\circ} \mathrm{C}$-ra. Berotze-hozte-berotze zikloak $50 \mathrm{~mL} / \mathrm{min}$ nitrogeno-fluxu baten pean gauzatuko dira.

\subsubsection{Azterketa termomekanikoa}

Azterketa termomekanikoa (Thermomechanical Analysis, TMA) materialaren propietate fisikoak aztertzeko erabiltzen den teknika da. Izenak 
adierazten duen moduan, tenperatura jakin batean eta indar bat aplikatuz (edo indarrik gabe), materialak azaltzen duen tamainaren edota propietate mekanikoaren aldaketa aztertzean datza.

Teknika hori sintetizaturiko poliuretanoen forma-memoria aztertzeko erabiltzen da. Horretarako, azterketa dinamiko mekaniko termikoarentzako erabili den ekipo berdina erabiltzen da, DMA-1 METTLER TOLEDO, baina oraingo honetan trakzio moduan. Erabiltzen den metodoan, lehenengo, laukizuzen formako lagin bat $\left(1,5 \times 5 \times 5 \mathrm{~mm}^{3}\right.$ bolumena) berotzen da minutu batean zehar, trantsizio-tenperaturaren gainetik, inongo indarrik aplikatu gabe $(\mathrm{F}=0)$. Ondoren, tenperatura konstantean $2 \mathrm{~N}$-eko indarra ezartzen da bost minutuan zehar, lagina luzatzea eraginez. Orduan, luzapen maximoa $\left(\mathrm{D}_{\max }\right)$ neurtzen da. Gero, indarra konstante mantenduz, lagina azkar hozten da $\left(20^{\circ} \mathrm{C} / \mathrm{min}\right), \mathrm{T}_{\mathrm{g}}$ baino balio baxuago batera eramanez eta horrela behin-behineko forma finkatuz $\left(D_{F}=0\right)$. Lagina hoztu denean, indarra kendu egiten da $(F=0)$, eta bost minutuan zehar mantentzen dira baldintza horiek. Azkenik, lagina berriro $\mathrm{T}_{\mathrm{g}}$ balioaren gainetik berotzen da, forma-memoria ezaugarria aktibatzeko eta laginak hasierako forma berreskura dezan $\left(D_{\mathrm{f}}\right)$.

Teknika horrek laginak jasandako deformazioa, finkapena eta berreskurapena ehunekotan kalkulatzea ahalbidetuko du (1-3) ekuazioen bidez.

$$
\begin{aligned}
& \operatorname{Deformazioa}(\%)=\left(\frac{D_{\max }}{L}\right) * 100 \\
& \operatorname{Finkapena}(\%)=\left(\frac{D_{F=0}}{D_{\max }}\right) * 100 \\
& \text { Berreskurapena }(\%)=\left(\frac{D_{\max }-D_{f}}{D_{\max }}\right) * 100
\end{aligned}
$$

\section{EMAITZAK ETA EZTABAIDA}

\subsection{Forma-memoria emaitzak}

Forma-memoria efektuaren analisia egiteko, lehendabizi tenperatura finkatu behar da; hau da, aldez aurretik sintetizaturiko materialen zati bigunaren $\mathrm{T}_{\mathrm{g}}$ balioa ezagutu behar da. Horretarako, ekorketazko kalorimetria diferentziala (DSC) teknika erabiltzen da. 7. irudian ikus dezakegu teknika horren bidez lortutako grafikoa nahaste batean $\mathrm{N}$ zenbaki desberdina izanda (PTMG1000-IPDI-CO, N = 3-6). Bertan, tenperatura handi- 
tzen denean gertatzen den bero-aldaketa zehazten da. Materiala egoera fisikoz aldatzen denean askatzen den tenperaturan ere aldaketa gertatuko da, eta grafikoan malda-aldaketa agertuko da. Malda-aldaketa horren hasieran materiala biguntzen hasiko da, eta bukaeran materiala guztiz bigun egongo da; beraz, $\mathrm{T}_{\mathrm{g}}$ balioa determinatzeko aldaketa horren erdiko puntua hartuko da, tenperatura hori izanik lagineko beira-trantsizioko tenperatura. Lagin horietan guztietan, bi $\mathrm{T}_{\mathrm{g}}$ balio desberdin agertuko dira: lehena zati bigunari dagokio, eta bigarrena zati gogorrari.

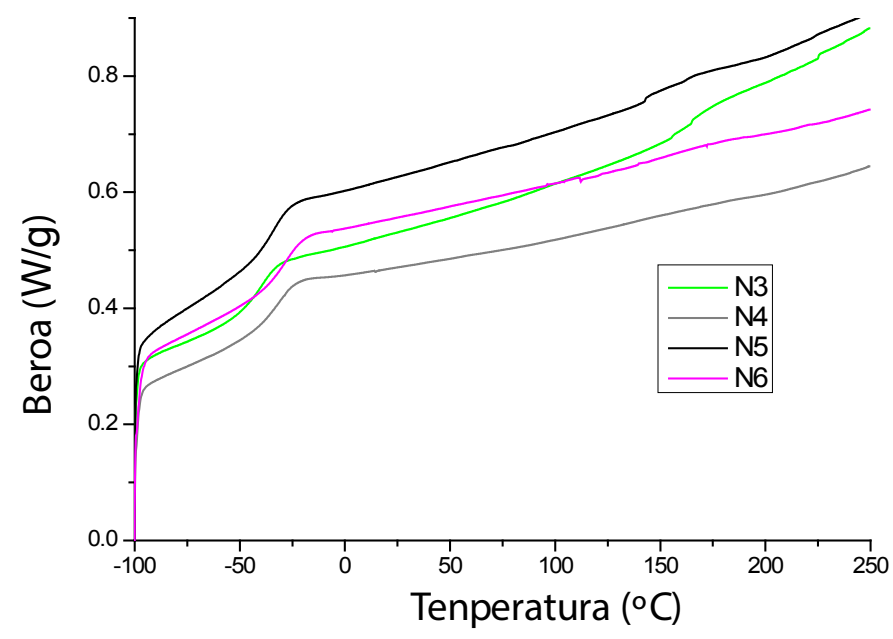

7. irudia. DSC grafikoak PTMG1000-IPDI-CO, N= 3-6 laginetan.

Teknika honen bidez, material guztien zati bigunaren $\mathrm{T}_{\mathrm{g}}$ balioak zehaztu dira; hots, ikusten diren lehengo beira-trantsizioak (2. taulan). 7. irudian, hauek dira PTMG1000-IPDI-CO laginentzako lortutako DSC grafikoetatik ateratako emaitzak: $-41,0^{\circ} \mathrm{C}(\mathrm{N}=3),-31,9^{\circ} \mathrm{C}(\mathrm{N}=4),-31,5^{\circ} \mathrm{C}(\mathrm{N}=5)$ eta $-29,8^{\circ} \mathrm{C}(\mathrm{N}=6)$. Ikusten den bezala, materialaren zati biguna erabat amorfoa da. Lehenengo trantsizioan ikusten denez, materialaren zati biguna erabat amorfoa da. Bestalde, lagin guztietan beirazko bigarren trantsizio bat ikusten da, zati gogorrari dagokiona. Kasu honetan, argi dago materialaren zati gogorra ere erabat amorfoa dela.

Datuetan ikusten den bezala, poliola bakarrik aldatzen den laginetan, hau da, PTMG1000 edo PTMG650 erabiltzerakoan, argi ikusten da PTMG1000 erabiltzen denean lortzen den $\mathrm{T}_{\mathrm{g}}$ balioa txikiagoa dela. Horrek zentzua dauka poliol kate lineala kasu honetan luzeagoa delako; beraz, segmentu biguna 
handiagoa izango da. Bestalde, ikusten da $\mathrm{N}$ balioa handitzen den heinean $\mathrm{T}_{\mathrm{g}}$ balioa handitu egiten dela. Efektu hori lotuta dago segmentu-proportzioekin ere; hau da, zenbat eta $\mathrm{N}$ balio altuagoa, orduan eta segmentu zurrunaren proportzio handiagoa izango da, eta, horregatik, $\mathrm{T}_{\mathrm{g}}$ balioa altuagoa da. Diisozianatoari dagokionez, HDI erabiltzen denean $\mathrm{T}_{\mathrm{g}}$ balio oso baxuak lortzen dira, eta, horregatik, hurrengo saioetan IPDI erabiltzea erabaki da. HDIk egitura lineala dauka, eta IPDIk ziklikoa; beraz, segmentu zurruna askoz zurrunagoa da IPDI erabilita, eta, horregatik, $\mathrm{T}_{\mathrm{g}}$ balioak igo egiten dira. Bestalde, kate hedatzailea konparatzen denean, $\mathrm{CO}$ erabiltzerakoan ikusi da $\mathrm{T}_{\mathrm{g}}$ balio txikiak lortzen direla. Hori dela eta, bi konposatuen batezbesteko $\mathrm{T}_{\mathrm{g}}$ balioa lortzeko, kate hedatzaileak nahasi egin dira proportzio berdinean-; baina lagin horiek bi $\mathrm{T}_{\mathrm{g}}$ balio desberdin erakusten dituzte, bakoitza kate hedatzaile batekin erlazionatuta dagoena; beraz, ondoriozta daiteke konposatu horiek bateraezinak direla. Horregatik, deuseztatu egin ziren lagin horiek.

2. taula. DSCtik lortutako $T_{g}$ balioak lagin desberdinetan, non kate hedatzaile bezala $\mathrm{CO}$ erabili baita.

\begin{tabular}{|c|c|c|}
\hline Lagina & $\mathrm{N}$ & $\mathrm{T}_{\mathrm{g}}\left({ }^{\circ} \mathrm{C}\right)$ \\
\hline \multirow{4}{*}{ PTMG1000-IPDI-CO } & 3 & $-41,0$ \\
\cline { 2 - 3 } & 4 & $-31,9$ \\
\cline { 2 - 3 } & 5 & $-31,5$ \\
\cline { 2 - 3 } & 6 & $-29,8$ \\
\hline \multirow{4}{*}{ PTMG1000-HDI-CO } & 1 & $-61,3$ \\
\cline { 2 - 3 } & 2 & $-56,3$ \\
\cline { 2 - 3 } & 3 & $-49,3$ \\
\cline { 2 - 3 } & 4 & $-49,2$ \\
\hline \multirow{4}{*}{ PTMG1000-IPDI-BD } & 2 & $-30,0$ \\
\cline { 2 - 3 } & 3 & 13,3 \\
\hline & 4 & 24,9 \\
\cline { 2 - 3 } & 5 & 27,8 \\
\hline
\end{tabular}

\begin{tabular}{|c|c|c|}
\hline Lagina & $\mathrm{N}$ & $\mathrm{T}_{\mathrm{g}}\left({ }^{\circ} \mathrm{C}\right)$ \\
\hline \multirow{4}{*}{ PTMG650-IPDI-CO } & 4 & $-34,7$ \\
\cline { 2 - 3 } & 5 & $-22,6$ \\
\cline { 2 - 3 } & 6 & $-21,3$ \\
\cline { 2 - 3 } & 7 & $-17,0$ \\
\hline \multirow{4}{*}{ PTMG650-HDI-CO } & 1 & $-53,3$ \\
\cline { 2 - 3 } & 2 & $-49,0$ \\
\cline { 2 - 3 } & 3 & $-41,5$ \\
\cline { 2 - 3 } & 4 & $-40,5$ \\
\hline \multirow{4}{*}{ PTMG650-IPDI-BD } & 1 & $-22,4$ \\
\cline { 2 - 3 } & 2 & 14,2 \\
\cline { 2 - 3 } & 3 & 25,3 \\
\cline { 2 - 3 } & 4 & 33,9 \\
\hline
\end{tabular}

Sintetizaturiko poliuretanoen forma-memoria ezaugarria aztertzeko, azterketa termomekanikoa (TMA) egin da. Bertan, laginak aurretik azaldutako berotze/deformazio/hozte/berotze prozesua jasaten du, eta horren aurrean azaltzen duen erantzuna aztertzen da. Lagin guztiek forma-memoria balio egokiak erakusten dituzte (3. taula). 
3.taula. Forma-memoria saiakuntzan lortutako balioak lagin desberdinetan.

\begin{tabular}{c|c|c|c|c}
\hline Lagina & $\mathrm{N}$ & $\begin{array}{c}\text { Deformazioa } \\
\left(\% \mathrm{D}_{\mathrm{F}}\right)\end{array}$ & $\begin{array}{c}\text { Finkapena } \\
\left(\% \mathrm{R}_{\mathrm{F}}\right)\end{array}$ & $\begin{array}{c}\text { Berreskurapena } \\
\left(\% \mathrm{R}_{\mathrm{R}}\right)\end{array}$ \\
\hline \multirow{4}{*}{ PTMG1000-IPDI-CO } & 4 & 11,20 & 93,06 & 89,65 \\
\cline { 2 - 5 } & 5 & 13,95 & 92,51 & 98,14 \\
\cline { 2 - 5 } & 6 & 9,92 & 90,90 & 97,41 \\
\hline \multirow{4}{*}{ PTMG650-IPDI-CO } & 4 & 11,20 & 93,06 & 89,65 \\
\cline { 2 - 5 } & 5 & 11,00 & 82,39 & 88,33 \\
\cline { 2 - 5 } & 6 & 13,53 & 52,75 & 93,08 \\
\cline { 2 - 5 } & 7 & 10,45 & 90,94 & 86,24 \\
\hline \multirow{4}{*}{ PTMG650-HDI-CO } & 2 & 7,70 & 85,60 & 100,00 \\
\cline { 2 - 5 } & 3 & 8,40 & 92,50 & 98,80 \\
\cline { 2 - 5 } & 4 & 8,70 & 94,10 & 99,90 \\
\hline
\end{tabular}

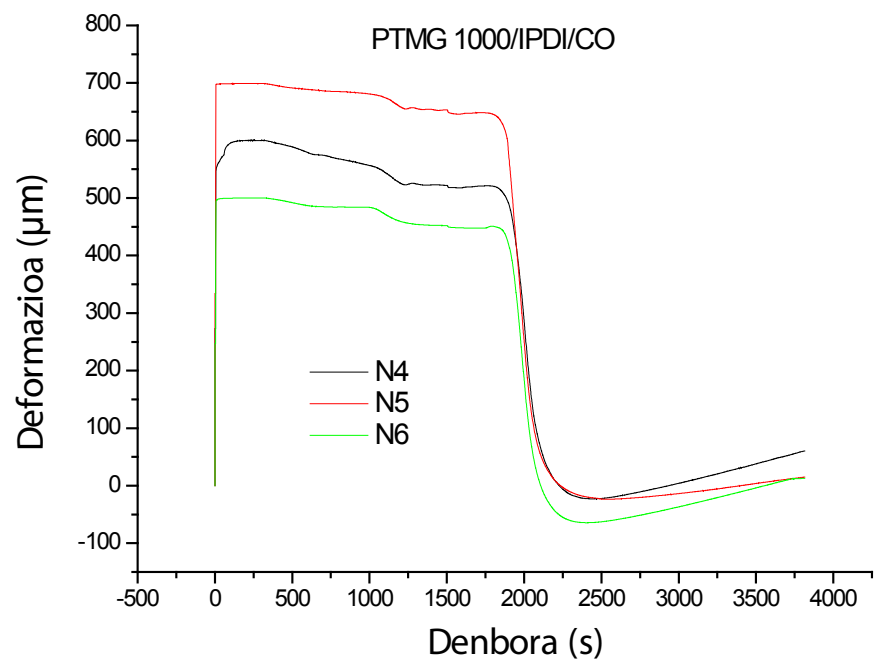

8. irudia. TMA teknikaren bidez lortutako grafikoak PTMG1000-IPDI-CO, N=4-6 laginetan. 
8. irudian ikus dezakegu teknika horren bidez lortutako grafikoa, nahaste batean $\mathrm{N}$ zenbaki desberdina izanda (PTMG1000-IPDI-CO, $\mathrm{N}=4-6)$. Kasu horretan, \% berreskurapena \% 90-98 izatea lortu da. Deformazioa egokia izan da ( \% 10) eta baita finkapena ere ( \% 90). Beraz, lagin horiek forma-memoria egokia azaltzen dutela aztertu da.

\subsection{Zitotoxizitatearen emaitzak}

PUen zitotoxizitatea aztertzeko, MTT teknikaren bidez (bromuro 3(4, 5 dimetil-2-tiazoil)-2,5-difeniltetrazolikoaren erredukzioa) lortutako emaitzak ikusiko dira [13]. Materialaren biobateragarritasuna zehazteko, lehenik inkubazio-denbora eta ondoren ugaritasun zelularra aztertzen dira, eta emaitzak portzentaje modura adierazten dira grafikoetan. Emaitza \% 100 bada, hasierako zelula guztiak bizirik daude, eta, beraz, materiala biobateragarria izango da ingurunean. Bestalde, emaitza \% 50 baino txikiagoa bada, materiala zalantzazko biobateragarria izango da.

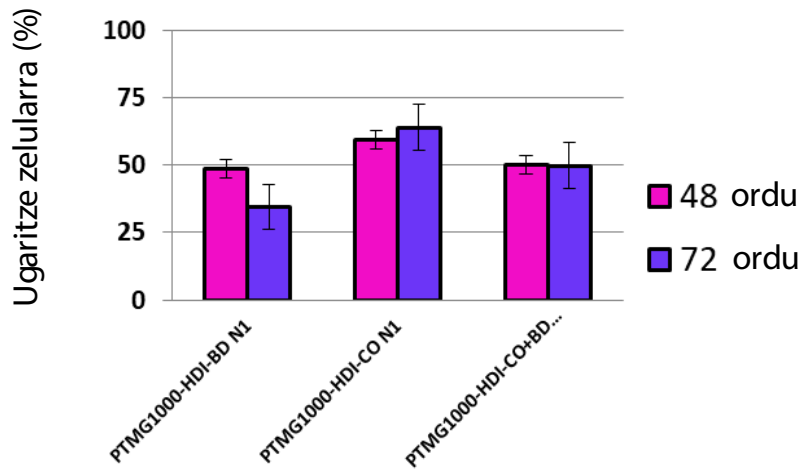

9. irudia. Ugaritze zelularra (\%) poliuretanoak Hek 293 (giza giltzurrunen zelula enbrionarioak) ingurune zelularrean 48 (arrosa) eta 72 (morea) ordu igaro ostean [13].

9. irudian agertzen dira PTMG1000-HDI-CO edota BD (N1) laginen 48 eta 72 orduko inkubazioa egin ondoren lortutako emaitzak. Bertan ikus dezakegu errizino-olioa kate hedatzaile modura duten konposatuak PU biobateragarriak eratzeko konposatu egokienak direla, \% 50 baino ugaritze zelular handiagoarekin. Ondoren, toxikotasun baxuena azaltzen duten hurrengoak $\mathrm{CO}$ eta butanodiol nahastea duten poliureta- 
noak dira, \% 50eko ugaltze zelularrarekin, eta, azkenik, kate hedatzaile modura soilik butanodiola duten konposatuak daude, \% 50 baino ugaritze zelular baxuagoarekin, hori zalantzazko material ez-toxiko izatea eraginez [13].

Ondoren, poliolaren pisu molekularraren eragina aztertzeko, aurretik biobateragarriena (CO kate hedatzailea) den konposatuaren bi lagin aztertu ziren, bat PTMG1000 zuena eta bestea PTMG650 zuena. Lortutako emaitzak ikusita, desberdintasun nabarmenik ez dagoela ondoriozta dezakegu. Beraz, poliolaren pisu molekularrak ez dauka eraginik PUaren biobateragarritasunean [13].

\section{ONDORIOAK}

Hasteko, esan beharra dago sintesietan PU egokiak lortu direla formamemoria emaitza egokiekin. Bestalde, laginen $\mathrm{T}_{\mathrm{g}}$ balioak aztertzen badira, horiek oso baxuak direla ikus dezakegu. Hala ere, taldeko beste lan batean lortutako emaitzekin alderatuz, non HDI isozianatoa erabili baita, IPDIrekin lortutako balioak egokiagoak izan dira, $\mathrm{T}_{\mathrm{g}}$ balioak igotzea lortu baita. Beraz, hori ikusita, arazo horri konponbide bat bilatzea posible dela adierazi da, sintesian erabilitako konposatuak aldatuz.

Gainera, aztertutako metodoarekin, ikusten da PTMGren pisu molekularrak ez duela eraginik materialaren zitotoxizitatean. Horrek materialaren segmentu bigunaren pisu molekularra aldatzea ahalbidetzen du, eta lortutako materialek ezaugarri desberdinak izatea eragiten; hau da, malguagoa edo zurrunagoa. Beste ondorio bat da kate hedatzailearen zitotoxizitatea. Butanodiolarekin lortutako materialak errizino-olioarekin lortutakoak baino toxikoagoak dira. Beraz, material horien sintesirako errizino-olioa egokiagoa dela ondorioztatzen da. Beraz, PTMG eta CO zitotoxizitaterik gabe biobateragarriak diren konposatuak dira.

Ondorioz, sintetizaturiko laginak forma-memoriaren eta toxizitatearen ikuspuntutik egokiak direla erabaki da. Hala ere, etorkizunean lagin horien $\mathrm{T}_{\mathrm{g}}$ tenperaturak igotzea lortu behar da aplikazio desberdinetan erabili ahal izateko.

\section{ESKER ONAK}

Egileek sostengu ekonomikoa eskertzen diete Eusko Jaurlaritzaren Ekonomiaren Garapena eta Azpiegituren Sailari, ELKARTEKi eta FRONTIERS IV-ri. Halaber, egileek esker onez onartzen dute Euskal Autonomia Erkidegoko Gobernuaren finantziazioa (IT718-13 ikerketataldea). 
Forma-memoria poliuretano biobateragarriak

\section{BIBLIOGRAFIA}

[1] Polyurethane demand worldwide from 2012 to 2022 (in million tons), Nov 11, 2019. https://www.statista.com/statistics/747004/polyurethane-demand-worldwide/ (acceso 12-05-2020).

[2] Boletín Vigilancia Tecnológica: Polímeros con memoria de forma $\left(\mathrm{N}^{\circ} 2\right.$, 15 Julio 2010). http://icono.fecyt.es/sites/default/files/filepublicaciones/bvt_ mat_n2.pdf

[3] KYU KIM B.; YUP LEE S.; XU M.. 1998. «Polyurethanes having shape memory effects». Polymer 37, 5781-93.

[4] LENDLEIN A.; KELCH S. 2002. «Shape-Memory Polymers». Angew. Chemie. Chem Int. 41, 2034-2057.

[5] ÇAKMAK E. G.; DLAGAKIRAN D.; GÜNER F. S. 2018. «Castor Oil and Peg-based Shape Memory Polyurethane films: effect of chain extender amount on some polymer properties and performance». Turk J Chem $\mathbf{4 2}$, 1161-1173.

[6] FURTWENGLER P.; AVÉROUS L. 2018. «Renewable Polyols for advanced polyurethane foams from diverse biomass resources». Polym. Chem. $\mathbf{9}$, 4258-4287.

[7] GITE V.V.; MAHULIKAR P.P.; HUNDIWALE D.G. 2010. «Preparation and properties of polyurethane coatings based on acrylic polyols and trimer of isophorone diisocyanate». Progress in Organic Coatings 68, 307-312.

[8] CHATTOPADHYAY D. K.; KOTHEPALLI R. KVSN. 2007. «Structural Engineering of Polyurethane Coatings for High Performance Applications». Progress in Polymer Science 32, 352-418.

[9] GUPTA A.; MAHARJAN A.; SOO KIM B. 2019. «Shape Memory Polyurethane and its Composites for Various Applications». Applied Sciences 21.

[10] BONFIL M.; SIRKECIOGLU A.; BINGOL-OZAKPINAR O.; URAS F.; GÜNER S. 2014. «Castor oil and PEG-Based Shape Memory Polyurethane Films for Biomedical Applications». Journal of Applied Polymer Science 131.

[11] TURAN D.; GUNES G.; GÜNER F. S. 2016. «Synthesis, Characterization and $\mathrm{O}_{2}$ Permeability of Shape Memory Polyurethane Films for Fresh Produce Packaging». Packaging Technology and Science 29, 415-427.

[12] ARÁN F.; MARTÍN J. M.; TORRÓ A. M. 2000. «Síntesis y caracterización de Poliuretanos termoplásticos que contienen resinas de colofonia y su aplicación como adhesivos». Tesis doctoral.

[13] TAGUADO M.; VILAS J. L.; VELOSO A. 2020. «Síntesis y caracterización de poliuretanos biocompatibles con memoria de forma». Trabajo de Fin de Grado. 
